\title{
ESTADO DA ARTE DE PUBLICAÇÕES SOBRE JUVENTUDES E EDUCAÇÃO EM REVISTAS A2 DE UNIVERSIDADES FEDERAIS BRASILEIRAS
}

\author{
STATE OF ART OF PUBLICATIONS ABOUT YOUTH AND \\ EDUCATION IN JOURNALS A2 OF BRAZILIAN FEDERAL \\ UNIVERSITIES
}

\author{
ESTADO DEL ARTE DE PUBLICACIONES ACERCA DE \\ JUVENTUDES Y EDUCACIÓN EN REVISTAS A2 DE \\ UNIVERSIDADES FEDERALES BRASILEÑAS
}

\author{
Victor Hugo Nedel Oliveira ${ }^{1}$ \\ ORCID: $h$ ttp://orcid.org/0000-0001-5624-8476
}

\begin{abstract}
Resumo: As produções sobre juventudes e educação apresentam importantes debates sobre os sujeitos jovens e suas relações com os processos educativos. Ao mesmo tempo, vêm ganhando destaque na agenda contemporânea, a partir da demanda acadêmica e social com a ampliação desse debate. O principal objetivo do presente texto foi construir o estado da arte das publicações sobre juventudes e educação, em revistas de Universidades Federais brasileiras, de classificação Qualis A2. Para tanto, realizou-se investigação bibliográfica que, inicialmente, selecionou os periódicos dispostos nos critérios estabelecidos e os textos para análise, a partir dos descritores "juventudes" e "jovens" e do recorte temporal de 2011 até 2020 . Foram analisadas questões referentes aos periódicos, às categorias temáticas e às tendências metodológicas apresentadas. Os resultados apontaram para a presença de 13 artigos, em periódicos das regiões nordeste, sudeste e sul do Brasil sem apresentar regularidade e em baixo volume de publicação. Os textos foram categorizados em três temas: juventudes periféricas; culturas juvenis; e juventudes e sexualidades. As tendências metodológicas apontam para investigações de abordagem qualitativa, que utilizam trabalhos de grupos e entrevistas como principais técnicas de coleta de dados, que utilizam da análise de conteúdo como principal recurso para análise dos dados, que investigaram sujeitos jovens e em cenários de pesquisa constituídos de espaços escolares. É possível considerar que a importância das investigações sobre juventudes e educação robustece a concepção da manutenção e ampliação do campo de pesquisa, abrindo novas possibilidades investigativas. Palavras-chave: Juventudes. Jovens. Educação. Estado da Arte. Revisão de Literatura. Revistas Científicas.
\end{abstract}

Abstract: The productions on youth and education present important debates on young subjects and their relationship with educational processes. At the same time, they have been gaining prominence in the contem-

1 Doutor e Pós-Doutor em Educação pela Pontifícia Universidade Católica do Rio Grande do Sul (PUCRS). Licenciado e Mestre em Geografia pela Universidade Federal do Rio Grande do Sul (UFRGS). Professor Adjunto e Pesquisador do Departamento de Humanidades da Universidade Federal do Rio Grande do Sul (UFRGS). Líder do Grupo de Estudos e Pesquisas em Juventudes e Educação (GEPJUVE/UFRGS/CNPq). 
porary agenda, from the academic and social demand with the expansion of this debate. The main objective of this text was to build the state of the art of publications on youth and education, in magazines of Brazilian Federal Universities, classified Qualis A2. To this end, a bibliographic investigation was carried out, which initially selected the journals arranged in the established criteria and the texts for analysis, from the descriptors "youths" and "youths" and from the time frame from 2011 to 2020. Questions related to journals, thematic categories and methodological trends presented. The results pointed to the presence of 13 articles in journals in the Northeast, Southeast and South regions of Brazil without regularity and low volume of publication. The texts were categorized into three themes: peripheral youth; youth cultures; and youth and sexualities. The methodological trends point to investigations with a qualitative approach, which use group work and interviews as the main data collection techniques, which use content analysis as the main resource for data analysis, which investigated young subjects and in research scenarios consisting of school spaces. It is possible to consider that the importance of research on youth and education strengthens the concept of maintaining and expanding the field of research, opening up new investigative possibilities.

Keywords: Youths. Youngs. Education. State of art. Literature Review. Scientific Journals.

Resumen: Las producciones sobre juventud y educación presentan importantes debates sobre temas jóvenes y su relación con los procesos educativos. Al mismo tiempo, han ido ganando protagonismo en la agenda contemporánea, desde la demanda académica y social con la ampliación de este debate. El objetivo principal de este texto fue construir el estado del arte de las publicaciones sobre juventud y educación, en revistas de las Universidades Federales de Brasil, clasificadas con Qualis A2. Para ello se llevó a cabo una investigación bibliográfica, en la que inicialmente seleccionó las revistas ordenadas según los criterios establecidos y los textos de análisis, a partir de los descriptores "juventudes" y "jóvenes" y del marco temporal de 2011 a 2020. Han sido analisados temas sobre las revistas, categorías temáticas y tendencias metodológicas presentadas. Los resultados apuntaron a la presencia de 13 artículos en revistas de las regiones Nordeste, Sudeste y Sur de Brasil sin regularidad y con bajo volumen de publicación. Los textos se categorizaron en tres temas: juventud periférica; culturas juveniles; y juventud y sexualidades. Las tendencias metodológicas apuntan a investigaciones con enfoque cualitativo, que utilizan el trabajo en grupo y las entrevistas como principales técnicas de recolección de datos, que utilizan el análisis de contenido como principal recurso para el análisis de datos, que investigaron sujetos jóvenes y en escenarios de investigación consistentes en espacios escolares. Es posible considerar que la importancia de la investigación sobre juventud y educación fortalece el concepto de mantener y ampliar el campo de investigación, abriendo nuevas posibilidades investigativas.

Palabras clave: Juventudes. Jóvenes. Educación. Estado del Arte. Revisión de Literatura. Revistas científicas.

\section{PARA INÍCIO DE CONVERSA}

O campo do saber e dos estudos e pesquisas sobre as juventudes contemporâneas assenta-nos frente à possibilidade de pesquisa sobre as múltiplas constituições dos sujeitos jovens, nos mais variados contextos da vida cotidiana. Constituem-se elementos de pesquisa relacionados às juventudes a cidade, o campo, a política, a diversidade, a religião e a escola, por exemplo². A partir desse contexto, reconhecer quem são as juventudes (PAIS, 1993) e a formação das culturas juvenis contemporâneas (FEIXA, 1998) implica em assu-

2 Distintos são os pesquisadores das juventudes nos campos elencados como exemplo. A título de reconhecimento e projeção, apresentam-se alguns deles, por tópico, a saber: cidade (OLIVEIRA, 2020a), campo 
mir um compromisso ético, estético e político na defesa da dignidade e da garantia e ampliação dos direitos desses sujeitos. O entendimento da condição e das diversas situações juvenis (ABRAMO, 1997) permite o alargamento dos escopos analíticos para a formação de elementos que auxiliem o entendimento de quem são os jovens contemporâneos, quais são suas demandas e necessidades e de quais questões sociais mais latentes reclamam. No campo da educação, espaço-tempo das juventudes por excelência, a presença dos jovens na escola (DAYRELL, 2007), na universidade, no mercado de trabalho, no desemprego, dentre outros contextos, favorece e impulsiona a investigação, de modo a conflagrar os cenários de pesquisa e potencializar o entendimento, a partir do método, de tais sujeitos.

Quando se coloca frente a um campo investigativo do qual múltiplos trabalhos são produzidos, constata-se a necessidade de executar uma mirada para a produção científica que vem sendo publicada, nesse caso, sobre as juventudes contemporâneas, e cultivar o desafio analítico de processar os avanços, os silenciamentos e as demandas de investigação sobre a temática das juventudes e suas diversas potencialidades de pesquisa. Ao longo da história acadêmica do país, importantes produções sobre as juventudes em nível de pós-graduação, por exemplo, foram lançadas. Ainda, trabalhos de graduação e de eventos científicos abordaram as temáticas sobre os jovens. Nos espaços de propagação científica com revisão por pares e indexação - ou seja, revistas e periódicos científicos - a produção sobre jovens também é constatada, entretanto, é escasso o conhecimento acerca dos movimentos dessa produção e das estratégias que vêm sendo empregadas para que o campo de pesquisa, em especial as relações dos jovens com a educação, ganhe maior destaque em tais veículos.

Para que se possa dar conta dessa pendência, as técnicas de construção do estado da arte (MOROSINI; FERNANDES, 2014) sobre a produção acadêmica de determinado campo do saber concentram-se com o efeito de reconhecer o estado atual das obras, as necessidades ainda não discutidas, as formas de encaminhamentos metodológicos das investigações, dentre outras tantas constatações e considerações possíveis. Nesse sentido, a construção do estado da arte das publicações em periódicos sobre juventudes e educação estabeleceu-se como principal objetivo do presente texto, a partir dos recortes e dos critérios previamente determinados. Quais são os principais objetos envolvendo os artigos sobre jovens e educação? Quais são os periódicos que mais apresentaram artigos sobre o tópico nos últimos 10 anos? Quais são as estratégias metodológicas mais recorrentes nessas investigações? São questões suleadoras ${ }^{3}$ das quais se buscam algumas definições - e suas discussões - ao longo do presente trabalho.

(WEISHEIMER, 2013), política (CORROCHANO; DOWBOR; JARDIM, 2018), diversidade (ABRAMOVAY et al, 2007), religião (NOVAES, 2012), escola (REIS, 2012).

3 À guisa de "Epistemologias do Sul", de Boaventura Santos e Maria Paula Meneses (2009), há que se voltar ao sul geográfico e social do mundo. Nesse sentido, as questões que nortearam o estudo igualmente se 
Estudos como o de Spósito (1997) já haviam buscado realizar a construção de estado do conhecimento de investigações que relacionassem o campo das juventudes e da educação, tendo importante contribuição ao debate dos avanços nessa seara e das necessidades latentes de pesquisa no campo. Para além do fato de que o estudo já tenha ultrapassado mais de 20 anos de sua realização, o mesmo havia se proposto, de modo central, a investigar os trabalhos em nível de pós-graduação stricto sensu no país, e não as publicações de periódicos, como é o caso do presente. Em sua pesquisa, a autora já havia apontado para o baixo número de produções sobre o tema, bem como pela dispersão entre múltiplos campos do saber, o que atribui aos estudos do gênero ampla variação temática. Nessa mesma linha de construção de pesquisas que buscassem levantar os estudos sobre juventudes, outros temas também já foram objetos de pesquisa, como o caso das políticas públicas para as juventudes, no estudo de Zanella et al (2013), ou, ainda, as vulnerabilidades e violências sofridas pelos jovens, a partir da pesquisa de Takeiti e Vicentin (2015). Há o entendimento de que as investigações anteriores que buscaram construir pesquisa do tipo estado da arte sobre as juventudes vêm apontado para a urgência investigativa do campo que, na contemporaneidade, vem adquirindo destacada relevância, tanto a partir do protagonismo juvenil em diversos elementos da vida cotidiana, quanto pela necessidade do melhor entendimento com os interlocutores jovens nas salas de aula, como é o caso do presente estudo.

Mais do que reunir a produção sobre as juventudes, pesquisas que elaboram o estado do conhecimento sobre determinados campos do saber objetivam-se em reconhecer o trabalho de pesquisadores que se dedicam ao campo, reverberar as discussões do tema e, ainda, instrumentalizar os atuais e futuros pesquisadores para que conheçam, a partir de análises já do que já foi produzido, o histórico e o andamento das pesquisas do campo em que trabalham. Nessa leitura, examinar o que vem se pesquisando sobre juventudes e educação é, portanto, procurar perceber as múltiplas realidades dos jovens e suas relações com a educação. É, sobretudo, afirmar que as juventudes importam para a educação e que a educação é importante para os jovens contemporâneos.

\section{PERCURSOS METODOLÓGICOS}

Tratou-se de pesquisa, em relação à abordagem, de cunho quantitativo-qualitativo (GIL, 2007), uma vez que os dados puderam ser extraídos em números e em múltiplos textos, a partir da construção de análise privilegiada das informações coletadas. Sob a ótica dos objetivos, tratou-se de investigação descritiva de caráter exploratório, uma vez que intencionalizou produzir maior proximidade com um tema em questão, sendo, no presente estudo, os debates sobre juventudes e educação em períodos do referido recorte temporal.

voltam para o "sul" das juventudes, para a mirada do periférico, daquele que está abaixo, à margem. 
Em relação aos seus procedimentos, constituiu-se de pesquisa bibliográfica que, no entendimento de acordo com Gil (2007), diz respeito às investigações que são elaboradas a partir de materiais já publicados, como artigos, livros e periódicos em geral. No caso da presente pesquisa, o levantamento bibliográfico assumiu a forma da construção do estado da arte (MOROSINI; FERNANDES, 2014), uma vez que objetivou verificar o quanto se desenvolveu, se cristalizou ou se redundou a investigação sobre juventudes e educação.

Para a seleção dos periódicos que compuseram o corpus da investigação, foi realizada busca e seleção no banco de dados do sistema CAPES-Qualis ${ }^{4}$, a partir de critérios previamente selecionados. O evento de classificação adotado foi a última avaliação de revistas oficial disponível, referente ao quadriênio de 2013 - 2016; já a área de avaliação selecionada foi a de educação; e, por fim, a classificação das revistas adotada foi a de A2, uma das mais altas, que é considerada de excelência. A classificação Qualis CAPES de avaliação de periódicos tem sido alvo de intensos debates no campo acadêmico, como apontam Frigeri e Monteiro (2014) tendo sido criado em 1998 com o principal objetivo de recomendar os canais de divulgação científica escrita de maior relevância em cada área do saber, no contexto brasileiro. As principais discussões a respeito desse sistema de classificação se dão em vários objetos, sendo a maioria em torno do agenciamento de políticas de produtivismo acadêmico, que ocorre a partir do ranqueamento dos periódicos científicos. Na classificação das revistas, utiliza-se a avaliação A (seguida dos números 1 ou 2, de reconhecimento de excelência internacional); $B$ (seguida dos números de 1 até o 5 , de reconhecimento de excelência nacional) e C (revistas não classificadas), tendo como critérios, por exemplo, o número de exemplares em circulação e sua periodicidade, o número de bases de dados e indexadores adotados pelo periódico, o número de instituições que publicam no periódico, a titulação dos autores dos artigos, dentre outros.

Na presente investigação, a escolha por periódicos de classificação A2 e aqueles baseados nas Universidades Federais brasileiras ocorreu pela conveniência de examinar a produção sobre juventudes e educação naqueles periódicos - para além da discussão sobre os critérios de seleção - que possuem alto grau de impacto. Em outras palavras, a partir dessa opção metodológica foi possível perceber quais produções sobre o tema possuem maior alcance nacional e internacional, permitindo, desse modo, expandir o debate sobre a classificação Qualis em si e sobre as produções encontradas. A partir do critério adotado de revistas A2 em Educação, foram localizados 380 periódicos, dos quais foram selecionados aqueles cujas instituições base eram Universidades Federais brasileiras. Dessa forma, para a triagem final dos periódicos, foram eleitos os 16 periódicos apresentados no quadro 1.

4 Disponível em: https://sucupira.capes.gov.br/sucupira/public/consultas/coleta/veiculoPublicacaoQualis/ listaConsultaGeralPeriodicos.jsf Acesso em: 20 jan. 2021. 
Quadro 1 - periódicos selecionados

\begin{tabular}{|l|l|}
\hline \multicolumn{1}{|c|}{ Revista } & \multicolumn{1}{c|}{ Universidade } \\
\hline Cadernos de História da Educação & Universidade Federal de Uberlândia \\
\hline Cadernos de Pesquisa & Universidade Federal do Maranhão \\
\hline Educação e Filosofia & Universidade Federal de Uberlândia \\
\hline Ensaio: pesquisa em Educação em Ciências & Universidade Federal de Minas Gerais \\
\hline Estudos de Literatura Brasileira Comparada & Universidade de Brasília \\
\hline Estudos de Psicologia & Universidade Federal do Rio Grande do Norte \\
\hline Fractal: Revista de Psicologia & Universidade Federal Fluminense \\
\hline Horizontes Antropológicos & Universidade Federal do Rio Grande do Sul \\
\hline Movimento & Universidade Federal do Rio Grande do Sul \\
\hline Perspectiva & Universidade Federal de Santa Catarina \\
\hline Repertório & Universidade Federal da Bahia \\
\hline Revista de Educação Pública & Universidade Federal do Mato Grosso \\
\hline Revista de Sociologia e Política & Universidade Federal do Paraná \\
\hline Revista Educação em Questão & Universidade Federal do Rio Grande do Norte \\
\hline Revista Educação Especial & Universidade Federal de Santa Maria \\
\hline Varia História & Universidade Federal de Minas Gerais \\
\hline
\end{tabular}

Organização: o autor (2021)

Tendo em mãos a seleção de periódicos tomada, passou-se à busca pelos textos que trabalhassem a temática proposta na pesquisa: juventudes e educação. Para isso, foi realizada busca nos arquivos dos periódicos, com recorte temporal adotado de 10 anos, compreendido entre os anos de 2011 até 2020 e com os seguintes descritores ou palavras-chave: "juventudes" e "jovens", utilizados em conjunto ou separadamente, de maneira a localizar o maior número de textos que estão relacionados ao campo de pesquisa das juventudes. O quadro 2 apresenta os 13 textos selecionados para a composição final do corpus da investigação.

Quadro 2 - composição do corpus da pesquisa

\begin{tabular}{|c|c|l|l|}
\hline Revista & $\begin{array}{c}\text { Volume, } \\
\text { número, ano }\end{array}$ & \multicolumn{1}{|c|}{ Título } & Primeiro/a Autor/a \\
\hline \multirow{2}{*}{$\begin{array}{c}\text { Cadernos } \\
\text { de Pesquisa } \\
\text { (UFMA) }\end{array}$} & $\begin{array}{c}\text { v. } 20, \text { n. 03, } \\
2013\end{array}$ & $\begin{array}{l}\text { Juventudes populares e projetos educacionais: } \\
\text { construção e fortalecimento de redes de solida- } \\
\text { riedade, afeto e sociabilidade }\end{array}$ & $\begin{array}{l}\text { ROSISTOLATO, } \\
\text { Rodrigo Pereira da } \\
\text { Rocha et al. }\end{array}$ \\
\cline { 2 - 4 } & $\begin{array}{c}\text { v. } 27, \text { n. 01, } \\
2020\end{array}$ & $\begin{array}{l}\text { Individuação em periferias e apropriação da edu- } \\
\text { cação: considerações desde a produção de nar- } \\
\text { rativas }\end{array}$ & $\begin{array}{l}\text { PINHEIRO, Leandro } \\
\text { Rogério. }\end{array}$ \\
\hline
\end{tabular}




\begin{tabular}{|c|c|c|c|}
\hline \multirow{2}{*}{$\begin{array}{l}\text { Estudos de } \\
\text { Psicologia } \\
\text { (UFRN) }\end{array}$} & $\begin{array}{l}\text { v. } 17, \text { n. } 03 \\
2012\end{array}$ & $\begin{array}{l}\text { Faces da juventude brasileira: entre o ideal e o } \\
\text { real }\end{array}$ & $\begin{array}{l}\text { SOUZA, Candida } \\
\text { et al. }\end{array}$ \\
\hline & $\begin{array}{l}\text { v. } 18, \text { n. } 02 \\
2013\end{array}$ & $\begin{array}{l}\text { Juventudes, movimentos e culturas: a participa- } \\
\text { ção política de jovens na cidade de Maceió. }\end{array}$ & $\begin{array}{l}\text { MESQUITA, Marcos } \\
\text { Ribeiro et al. }\end{array}$ \\
\hline \multirow{4}{*}{ Fractal (UFF) } & $\begin{array}{l}\text { v. } 25, \text { n. } 01 \\
2013\end{array}$ & $\begin{array}{l}\text { "Meu prazer agora é risco": sentidos sobre sexu- } \\
\text { alidade entre jovens de um grupo sobre saúde }\end{array}$ & $\begin{array}{l}\text { BARROS, João Pau- } \\
\text { lo Pereira et al. }\end{array}$ \\
\hline & $\begin{array}{l}\text { v. } 29, \text { n. } 01 \\
2017\end{array}$ & $\begin{array}{l}\text { Travestis brasileiras e escola: problematizações } \\
\text { sobre processos temporais em gêneros, sexuali- } \\
\text { dades e corporalidades nômades. }\end{array}$ & $\begin{array}{l}\text { SALES, Adriana et } \\
\text { al. }\end{array}$ \\
\hline & v. 31,2019 & $\begin{array}{l}\text { Cultura hip-hop e enfrentamento à violência: uma } \\
\text { estratégia universitária extensionista }\end{array}$ & $\begin{array}{l}\text { IMBRIZI, Jaquelina } \\
\text { Maria et al. }\end{array}$ \\
\hline & v. 31,2019 & $\begin{array}{l}\text { Juventude(s) periférica(s) e subjetivações: narra- } \\
\text { tivas de (re)existência juvenil em territórios cul- } \\
\text { turais }\end{array}$ & $\begin{array}{l}\text { TAKEITI, Beatriz } \\
\text { Akemi et al. }\end{array}$ \\
\hline $\begin{array}{l}\text { Movimento } \\
\text { (UFRGS) }\end{array}$ & v. 25,2019 & $\begin{array}{l}\text { A percepção das juventudes a respeito dos seus } \\
\text { processos de identidades e suas apropriações } \\
\text { para além do jogador Neymar }\end{array}$ & $\begin{array}{l}\text { FELTES, Alessandra } \\
\text { Fernandes et al. }\end{array}$ \\
\hline \multirow[t]{2}{*}{$\begin{array}{l}\text { Perspectiva } \\
\text { (UFSC) }\end{array}$} & $\begin{array}{l}\text { v. } 33, \text { n. } 02 . \\
2015\end{array}$ & $\begin{array}{l}\text { Las condiciones del aprendizaje escolar, las } \\
\text { culturas juveniles y uso de TICs en el ingreso a la } \\
\text { Escuela Media: los problemas en la transmisión } \\
\text { entre jóvenes y profesores }\end{array}$ & VILLA, Alejandro \\
\hline & $\begin{array}{l}\text { v. } 37, \text { n. } 01 \\
2019\end{array}$ & $\begin{array}{l}\text { Os selfies e o corpo tombamento: reflexões a } \\
\text { partir de uma autoimagem sonora }\end{array}$ & $\begin{array}{l}\text { SANTOS, Edmea } \\
\text { Oliveira dos et al. }\end{array}$ \\
\hline $\begin{array}{l}\text { Revista de } \\
\text { Sociologia } \\
\text { e Política } \\
\text { (UFPR) }\end{array}$ & $\begin{array}{l}\text { v. } 25, \text { n. } 64 \text {, } \\
2017\end{array}$ & $\begin{array}{l}\text { Activismo juvenil en partidos con gestiones de } \\
\text { gobierno a nivel subnacional en Argentina (2007- } \\
\text { 2015) }\end{array}$ & $\begin{array}{l}\text { VAZQUEZ, Melina } \\
\text { et al. }\end{array}$ \\
\hline $\begin{array}{l}\text { Revista } \\
\text { Educação } \\
\text { em Questão } \\
\text { (UFRN) }\end{array}$ & $\begin{array}{l}\text { v. } 58, \text { n. } 58 \\
2020\end{array}$ & $\begin{array}{l}\text { Amor, sexo e distância física: Pedagogias do } \\
\text { Webnamoro na pandemia da Covid-19 }\end{array}$ & $\begin{array}{l}\text { SILVA JÚNIOR, } \\
\text { Alcidesio Oliveira da } \\
\text { et al. }\end{array}$ \\
\hline
\end{tabular}

Organização: o autor (2021)

Foi realizada a leitura dos 13 textos que foram encontrados e selecionados para construção do corpus da pesquisa e, dos mesmos, foram retiradas as seguintes informações: os dados gerais da publicação (ano, volume, número, título, autor/es); o tema geral do trabalho (a partir de discussão das múltiplas formas de apresentação dos temas) e os tópicos relacionados à metodologia das pesquisas que formaram os textos (quanto à abordagem, ao instrumento, ao método de análise, à população e ao cenário). $A$ análise dos dados, que combinou o escopo analítico estatístico (LEVIN, 2007) e a análise de conteúdo (BARDIN, 1977), possibilitando a construção de gráficos, quadros e esquemas que demonstrassem as tendências e as singularidades dos trabalhos, de maneira a reconhecer tanto os avanços como os silenciamentos sobre o debate contemporâneo acerca das juventudes nos periódicos de maior alcance e impacto na realidade brasileira. 
Em atendimento aos mais altos padrões de cuidados éticos na pesquisa em ciências humanas, a investigação encontrou-se com dispensa de análise do Comitê de Ética em Pesquisa, já que se tratou de estudo bibliográfico, com material já publicado, sendo amparada na Resolução 510/2016 (BRASIL, 2016) do Conselho Nacional de Saúde.

\section{ACHADOS E DISCUSSÕES}

Primeiramente, se torna conveniente o emprego da discussão sobre o quantitativo de artigos encontrados por periódico e suas considerações subsequentes, pelo que pode ser examinado no gráfico 1.

Gráfico 1 - número de trabalhos por revista

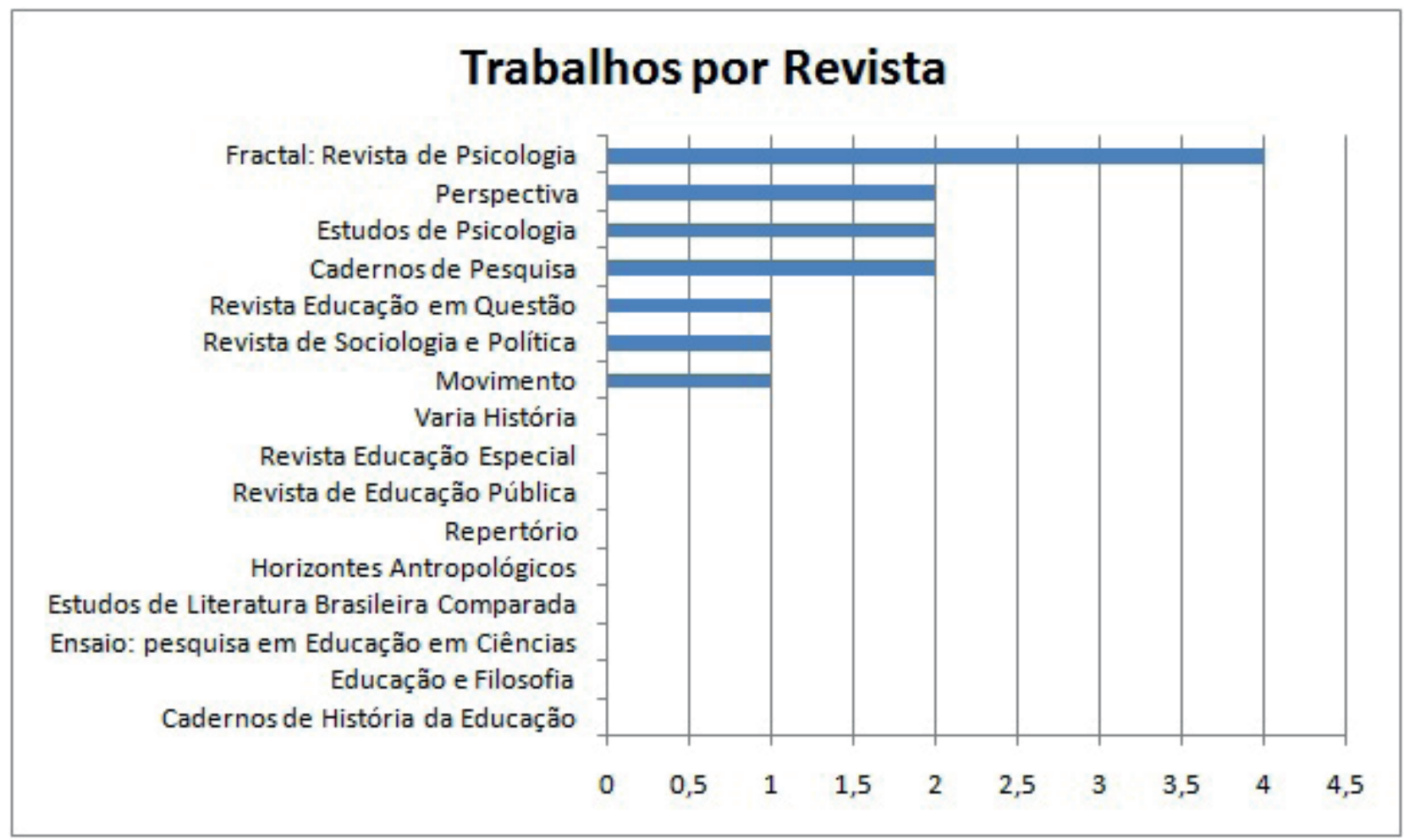

Fonte: Banco de dados da Pesquisa (2021). Organização: o autor (2021)

Dos 13 trabalhos que compuseram o corpus da presente investigação, $31 \%(n=4)$ foram encontrados na Fractal: Revista de Psicologia, da Universidade Federal Fluminense (UFF); 15\% ( $n=2)$ na Revista Perspectiva, da Universidade Federal de Santa Catarina (UFSC); outros 15\% ( $n=2)$ na Revista Estudos de Psicologia, da Universidade Federal do Rio Grande do Norte (UFRN); e outros 15\% ( $n=2)$ na Revista Cadernos de Pesquisa, da Universidade Federal do Maranhão (UFMA). Os periódicos: Educação em Questão (Universidade Federal do Rio Grande do Norte), Sociologia e Política (Universidade Federal do Paraná) e Movimento (Universidade Federal do Rio Grande do Sul) figuraram com 1 texto (8\%) cada. Não foram localizados trabalhos nas outras nove revistas com Qualis A2 
de Universidades Federais brasileiras, portanto, o fato de que apenas 43,75\% ( $n=7)$ dos periódicos selecionados para investigação apresentaram trabalhos com os descritores e o recorte temporal adotados já se configura como dado inicial que aponta para a possível baixa produção no campo, a partir do cenário estabelecido. Cabe destacar que dos sete periódicos que apresentaram trabalhos apenas três possuem vinculação direta com o campo da educação e seus pesquisadores, nas universidades correspondentes. Os demais periódicos são do campo da psicologia (2), sociologia (1) e educação física (1), o que aponta, igualmente, para a multidimensionalidade e amplitude temática já verificadas nas pesquisas sobre juventudes.

Em relação à seleção dos periódicos e, posteriormente, à composição daqueles que apresentaram textos no corpus da investigação, um encontra-se na região sudeste, três na região sul e três na região nordeste do Brasil. Essa informação coloca-nos frete aos estudos propostos por Santos (1986), quando sugeriu, a partir da regionalização do Instituto Brasileiro de Geografia e Estatística (IBGE), o debate sobre o que viria a ser nomeada a "região concentrada", que conglomeraria as regiões sul e sudeste do país. Esses estudos confirmaram, já à época, que a região concentrada configurava-se como aquela produtora das principais riquezas do país ${ }^{5}$, tanto as materiais, como também aquelas que dificilmente poderiam ser solidificadas, como é o caso da produção científica. Nesse entendimento, a produção sobre juventudes e educação, na última década e a partir do cenário estabelecido, também acompanhou a concentração na mesma região proposta pelo geógrafo Milton Santos. Ainda, é de destaque analítico fundamental a presença da região nordeste, com três periódicos que apresentaram textos, dentro do corpus da pesquisa, uma vez que se trata de região do país que, histórica e recorrentemente vem apresentando postura de esclarecimento e entendimento social das mazelas e demandas principalmente das classes populares do país ${ }^{6}$. Nesse sentido, encontrar textos sobre juventudes e educação em periódicos da região nordeste comprova a ligação epistemológica entre o objeto de estudo e a opção por publicação adotada.

Outra análise que requer especial atenção diz respeito à produção ao longo do período estabelecido como recorte temporal da investigação, qual seja, a década compreendida entre os anos de 2011 e 2020, pelo que foi possível realizar a construção do gráfico 2, que segue.

5 Tal concentração, segundo o autor, se deu pelo desenvolvimento dos processos de uso e ocupação do espaço ao longo da formação do território brasileiro, que privilegiou as regiões apontadas no desenvolvimento técnico-científico-informacional.

6 Ancorando-se em Furtado (1984), Jungbluth e Souen (2010) e outros autores, entende-se que os processos de desvalorização da região, ao longo do tempo, contribuíram na construção do cenário socioeconômico encontrado atualmente no nordeste do Brasil. Esses e outros fatores vêm corroborando no entendimento que a maioria dos habitantes da região possui em relação ao campo político do país, apresentando posições inclusive eleitorais - em geral voltadas à justiça social e diminuição das desigualdades. 
Gráfico 2 - número de trabalhos por ano

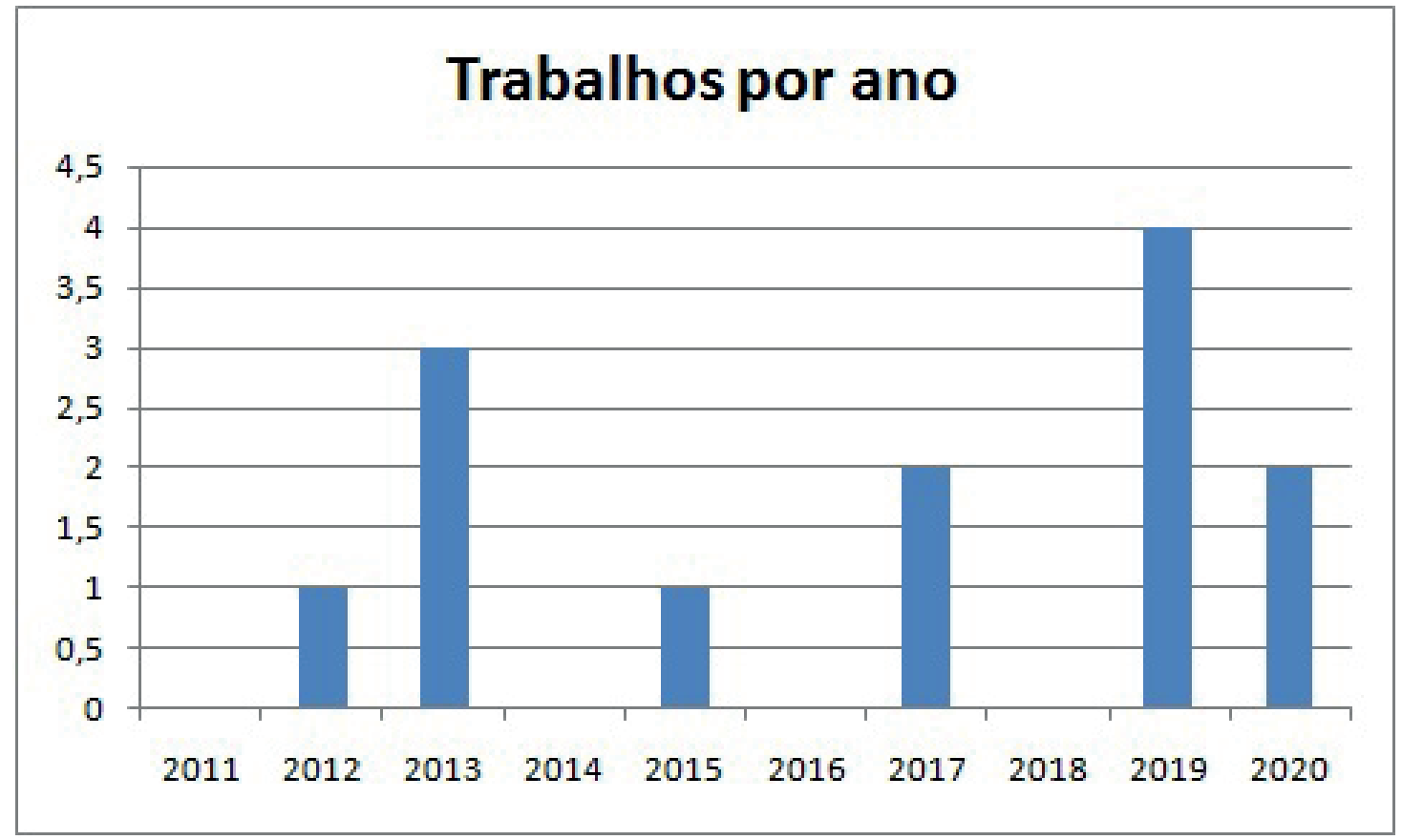

Fonte: Banco de dados da Pesquisa (2021). Organização: o autor (2021)

O ano que mais apresentou trabalhos foi 2019 , com $31 \%(n=4)$ dos textos selecionados para a investigação. À exceção dos anos de 2011, 2014, 2016 e 2018, que não apresentaram trabalhos, nos demais foram constatados de 1 (8\%) até $3(24 \%)$ dos trabalhos em cada. A leitura e a análise do gráfico tornam possível perceber que não existe certa regularidade na produção sobre juventudes e educação nos periódicos com classificação A2 de Universidades Federais, bem como, é possível considerar a produção, quantitativamente, baixa, sopesando o tamanho e as potencialidades analíticas que poderiam ser empregadas na adoção da temática das juventudes e educação enquanto possibilidade investigativa. Cabe destacar que não foram identificados, no período e nos periódicos selecionados, dossiês ${ }^{7}$ que buscassem promover discussão sobre as juventudes e suas áreas proximais do campo de pesquisa.

Em sintonia com as constatações já realizada, fica evidente o baixo número de trabaIhos verificados ao longo de 10 anos, que, em média, apresentaria em torno de um por ano. Alguns motivos principais poderiam ser entendidos como justificativa para o cenário encontrado. O primeiro, diz respeito a certa dificuldade de acesso à publicação em periódicos de Qualis elevados, como é o caso das revistas A2, uma vez que, nesses veículos, muito dificilmente são aceitos autores que não sejam doutores, para além do eventual longo período de tempo para as avaliações dos manuscritos, o que acaba, por sua vez, desestimulando

7 A prática da organização de dossiês em revistas científicas vem sendo adotada como forma de explorar com maior profundidade determinados temas que entram na agenda dos pesquisadores, bem como de evidenciar as temáticas de interesse dos corpos editoriais, a partir do escopo de cada periódico. 
os pesquisadores na submissão de textos nos periódicos mais bem avaliados. Ainda, é possível identificar que o campo de pesquisa sobre juventudes encontra, sistematicamente, algumas dificuldades político-acadêmicas no que diz respeito à sua consolidação, prova disso é o fato de não existir um grupo de trabalho (GT) específico sobre a temática nas reuniões da Associação Nacional de Pós-Graduação e Pesquisa em Educação (ANPEd) ou, ainda, a confusão teórica recorrentemente verificada com o campo de pesquisa da adolescência (ABRAMO; LEÓN, 2005), o que, em algum grau, aumenta a invisibilidade dos pesquisadores das juventudes.

De posse dos 13 textos que compuseram o corpus da pesquisa, os arquivos eletrônicos dos mesmos foram submetidos à plataforma de análise qualitativa Voyant Tools ${ }^{8}$, de modo a que fosse possível a elaboração da nuvem com as 35 palavras e/ou expressões de maior incidência nos textos, apresentada na figura 1. Enfatiza-se que, quanto maior a palavra é apresentada, maior é o número de ocorrências da mesma ao longo da análise qualitativa.

Figura 1 - nuvem de palavras elaborada a partir dos textos selecionados

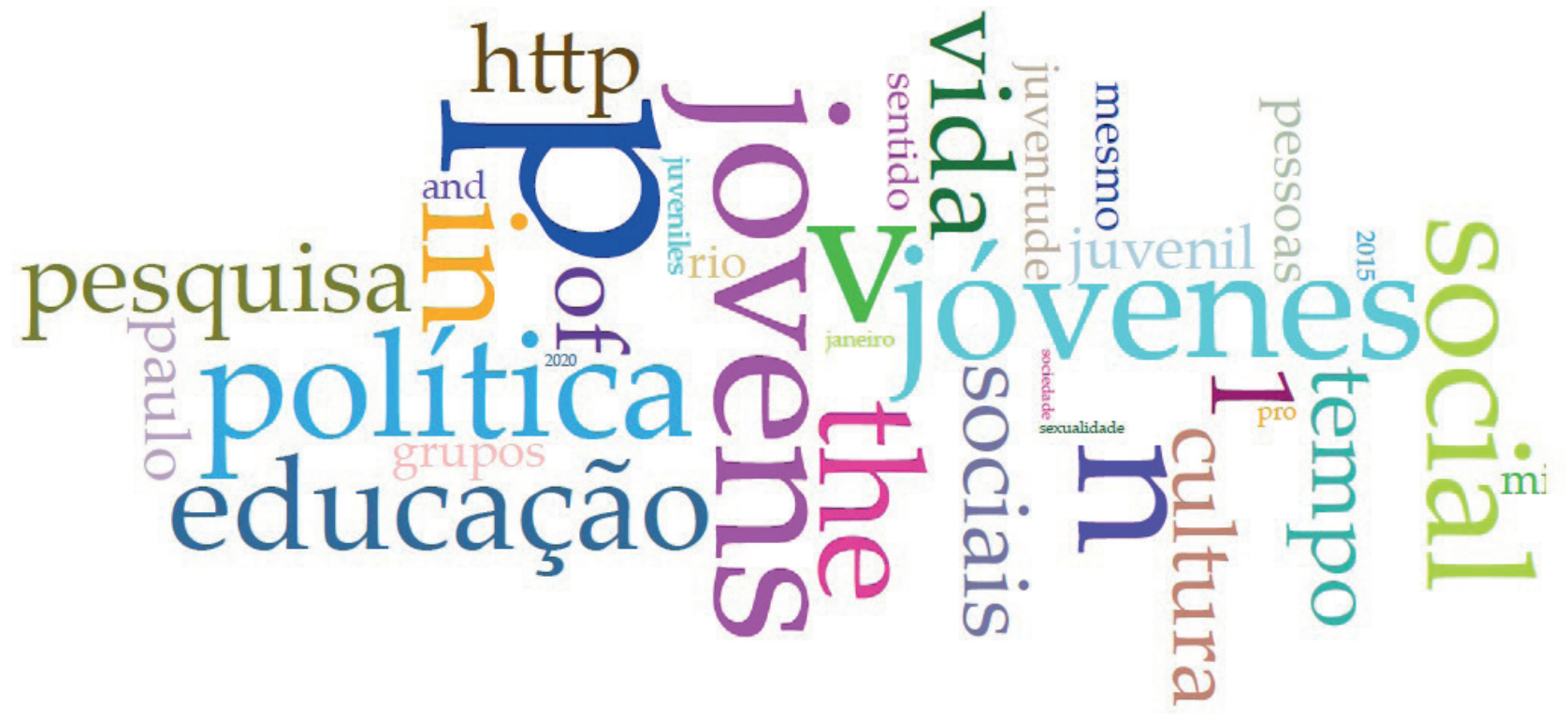

Fonte: Banco de dados da Pesquisa (2021). Organização: o autor (2021)

As expressões "jovens", "jóvenes", "juvenil" e "juventude" estão associadas diretamente aos sujeitos centrais do campo de investigação em análise: as juventudes. Nesse sentido, em associação às leituras de Feixa (1998) há o entendimento de que as culturas juvenis são formadas a partir das relações juvenis que se dão pela passagem da coletividade. Assim, verifica-se que não há uma única maneira de ser ou de estar jovem no mundo contemporâneo, mas

8 Disponível em: https://voyant-tools.org/ Acesso em: 20 jan. 2021. 
múltiplas. É dessa compreensão de procede o recorrente uso das expressões "juventudes" e "jovens", no plural, em contraposição do uso das expressões no singular, de forma a expressar a dimensão do coletivo e da diversidade. Ao mesmo tempo, a expressão "educação" também apareceu em destaque, uma vez que os trabalhos que compuseram o corpus da investigação debateram, em um largo espectro, as questões relativas aos jovens e à educação, sendo publicados em periódicos específicos da área de educação, com avaliação Qualis elevada.

Outras expressões também ocorreram em maior grau na nuvem de palavras apresentadas, como, por exemplo: "social" ou "sociais"; "política", "pesquisa", "cultura", "vida" e "tempo", sendo as expressões que apresentam as nuances das investigações e dos meandros pelos quais cada uma percorreu. As expressões "social" ou "sociais" evidenciam, em uma primeira leitura, as preocupações dos artigos em refletir, promover ponderação e potencializar a discussão em torno das questões sociais das juventudes. Ao debruçar esforços analíticos nas juventudes brasileiras, a temática social, dessa forma, teria que ser apresentada, já que as desigualdades existentes na sociedade brasileira (OLIVEIRA, 2020b) são cada vez maiores. Ainda, a expressão "tempo" apresenta ideia da dimensão temporal-analítica dos textos que compuseram o corpus da investigação, pois também se tratam de estudos cujas preocupações recaem sobre as possibilidades de futuro das juventudes, em relação ao transcorrer do tempo e aos seus projetos de vida. As expressões "política", "cultura" e "vida", de certo modo, apontam para outro direcionamento analítico, o qual se preocupou em analisar os impactos de políticas e das produções culturais nas trajetórias dos jovens.

Em conjunto à construção da nuvem de palavras contendo as expressões mais recorrentes na integralidade dos textos analisados, também foi possível construir, por meio da plataforma Voyant Tools um esquema que apresentasse as relações entre as expressões mais utilizadas no conjunto dos textos estudados. Para tanto, a figura 2 apresenta o que se denominam de "nós" das expressões em evidências.

Figura 2 - nós das expressões mais recorrentes e suas relações

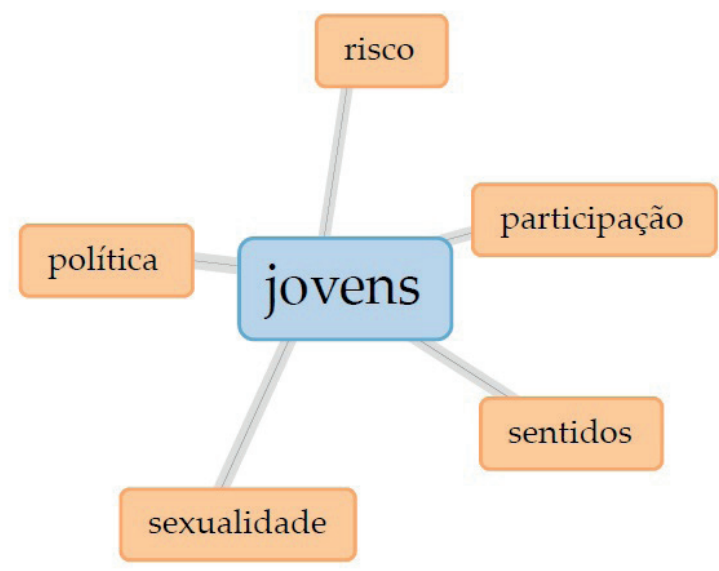

Fonte: Banco de dados da Pesquisa (2021). Organização: o autor (2021) 
É possível averiguar a centralidade da expressão "jovens" e sua ligação primária com as expressões "participação", "sentidos", "sexualidade", "política" e "risco" que são, a partir da análise qualitativa, os principais pontos de encontro nas discussões sobre as juventudes, no material analisado. Em outras palavras, os textos, em sua maioria, preocupam-se em verificar os sentidos que os jovens atribuem para os diversos campos de suas vidas, dentre eles a política e a sexualidade, avaliando sua participação e os riscos que dela poderiam decorrer. Em resumo, as relações encontradas nos nós dos textos analisados versam sobre os jovens, apresentando reflexões acerca dos projetos de vida e de futuro desses sujeitos.

Ao analisar os 13 trabalhos que formaram o corpus da investigação, foi possível elaborar categorização que encontrasse temas em comum nos artigos analisados. $O$ gráfico 3 apresenta, dessa foram, as três categorias construídas a partir da análise prévia dos trabalhos.

Gráfico 3 - número de trabalhos por tema/categoria

\section{Trabalhos por Tema/Categoria}

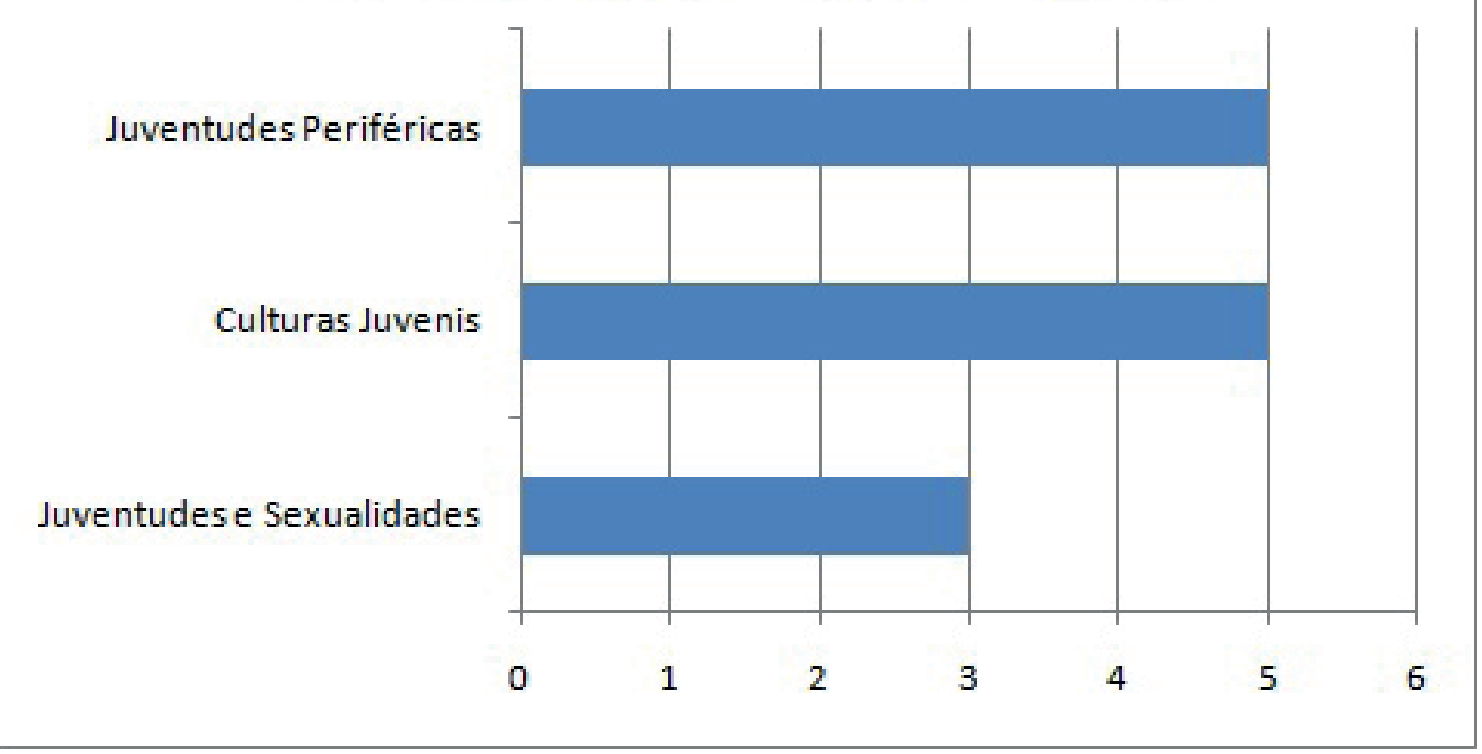

Fonte: Banco de dados da Pesquisa (2021). Organização: o autor (2021)

A categoria denominada Juventudes Periféricas abarcou 38\% $(n=5)$ dos trabalhos e, dentre eles, encontrou-se o texto de Pinheiro (2020) buscou analisar contextos juvenis em periferias urbanas de Porto Alegre, construindo entendimento sobre os processos de individuação a partir de quatro domínios sociais: território, trabalho, família e escolarização. As duas grandes considerações da pesquisa giram em torno dos desvios encontrados nas práticas educativas, em detrimento da necessidade de inserção dos sujeitos no mundo do trabalho. O trabalho de Takeiti e Vicentin (2019), por sua vez, tratou de três processos rela- 
cionados às juventudes periféricas: vitimização, criminalização e estigmatização. As autoras utilizam-se da arte enquanto ações culturais de apropriação dos territórios, em especial o sarau, o cinema e o hip hop. Constatam que a arte fomenta possibilidades de intervenção nos territórios existenciais dos jovens, na medida em que a estigmatização se transforma em orgulho, de ser jovem, negro, pobre e periférico.

A produção de Vazquez e Cozachcow (2017), por sua vez, constitui-se uma das duas produções em idioma estrangeiro - língua espanhola - e apresenta discussão sobre os modos de participação política que os jovens da Argentina encontram em espaços político-partidários. O texto foi alocado na presente categoria, uma vez que compreende a participação política das juventudes como forma de ativismo e, nessa leitura, de resistência e contraposição ao dominante. O artigo de Rosistolato et al (2013) promove debate sobre o que denominam de "produto final" da educação para jovens de classes populares, na realidade do Rio de Janeiro. Os autores têm como sujeitos da investigação jovens pobres, com ensino médio concluído e que almejam ingressar no Ensino Superior, dentre seus esforços, a partir da participação em pré-vestibular popular. O texto pode analisar as narrativas dos jovens dando foco nas emoções que foram associadas às perspectivas de mudanças em suas vidas. Por fim, nessa categoria, o trabalho de Souza e Paiva (2012) buscou conceituar a ideia de juventude, a partir dos processos de construção social empregados em seus resgates. Um dos aspectos que ressalta a análise no texto são os processos constantes de violações dos direitos humanos dos sujeitos jovens, o que os coloca, em determinado grau, à margem - na periferia - da sociedade contemporânea.

Os cinco textos que formaram a categoria "juventudes periféricas" trabalharam, a seu modo, alguns dos processos que fazem com que as juventudes contemporâneas sejam colocadas nas periferias da sociedade. Espacialmente, tratam-se dos sujeitos pobres, que vivem distantes dos centros de suas cidades. Temporalmente, tratam-se dos sujeitos que apenas vivem a juventude como transição para a vida adulta, tendo que empregar-se muito cedo para colaborar no sustento da casa. Socialmente, tratam-se dos sujeitos que estão à margem do acesso e permanência no ensino superior, por exemplo, dadas as condições de desigualdades sociais que há séculos imperam no cotidiano do Brasil e da América Latina como um todo; aquela região que há mais de 500 anos sangra ${ }^{9}$, cujo sangue serviu de alimento e riqueza aos dominadores. Sangue muitas vezes juvenil.

Na categoria Culturas Juvenis outros 38\% $(n=5)$ dos trabalhos foram identificados e o texto de Feltes e Sanfelice (2019) buscou analisar a construção de identidades juvenis a partir da apropriação da figura do jogador Neymar. A pesquisa foi realizada com jovens de uma escola privada de Novo Hamburgo (RS), inseridos em grupos correspondentes à sua prática sociocultural, como teatro, grêmio estudantil e atletismo. O consumo para manter a garantia de padrões e status social foi constatado entre os jovens, entretanto, a figura do re-

9 Em alusão à magistral obra de Eduardo Galeano: As veias abertas da América Latina (2000). 
ferido jogador não surgiu como referência aos jovens do estudo. O trabalho de Imbrizi et al (2019) discutiu a cultura do hip-hop como potencializadora nas estratégias de enfrentamento à violência. Os autores apresentam um projeto de extensão universitária, denominado "Escuta Clínico-Política de Sujeitos em Situações Sociais Críticas", cujo principal objetivo constituiu-se de ouvir as mães que perderam seus filhos em situações de violência. No referido projeto, uma das ações foi a roda de conversas intitulada "Hip-hop e o enfrentamento à Violência", na qual as manifestações culturais da arte emergiram como pontos de contatos com as juventudes em múltiplos aspectos.

Santos e D’Ávila (2019), por sua vez, trabalharam com a temática do "tombamento" entendido como um manifesto estético-artístico que ocorre nos corpos dos jovens contemporâneos, aqueles que, de acordo com as autoras, são os que "afrontam", que se apropriam das redes sociais; que são da periferia; que criam novas narrativas e referências, apropriando-se de novos espaços que, normalmente, antes não lhes eram permitidos ou não possuíam acesso. Villa (2015), por sua vez, trabalha com as questões relacionadas às culturas juvenis e o uso das novas tecnologias no aprendizado de jovens estudantes do ensino médio, na realidade argentina, sendo o segundo de dois textos em idioma estrangeiro, que formaram parte do corpus analítico. O autor aponta para três debates fundamentais: a massificação do consumo entre jovens; a dissociação, na sala de aula, entre as interações entre os pares e o consumo; e os processos de perda de atenção dos estudantes durante as aulas, em decorrência do uso excessivo das novas tecnologias. Ainda, nessa categoria, Mesquita e Oliveira (2013) debatem os movimentos e as culturas de jovens de Maceió (AL) a partir de suas participações políticas de militância. Os autores constatam a multiplicidade de discursos a respeito da política, tendo como contextos grupos e movimentos dos âmbitos político, religioso e cultural/comunitário. Verificam, ainda, o desejo da juventude de estar conectada com seu tempo e a necessidade de ser percebida como sujeitos sociais.

Os textos que compuseram a categoria "culturas juvenis" evidenciaram aquilo que Feixa (1998) já apontava como mótus fundante do conceito que trabalhara: a coletividade. São pesquisas que evidenciam o contato social dos jovens e as diversas produções de sociabilidades desses sujeitos. Nessa leitura, não há como entender as juventudes contemporâneas sem, ao mesmo tempo, promover o entendimento de sua atuação no coletivo, seja através de grupos institucionalizados ou espontâneos. O estar junto, o produzir junto, o lutar junto, o viver junto emerge como tendência nessa categoria estudada.

Por fim, a categoria Juventudes e Sexualidades, com 24\% $(n=3)$ dos trabalhos apresentaram temas que pautavam a discussão das juventudes com elementos diretamente relacionados às questões de produção de sexualidades. O trabalho de Silva Júnior, Félix e Couto (2020) apresentou debate contemporâneo, acerca das novas constituições de amor, namoro e sexo à distância, em tempos de pandemia da Covid-19, através de estudo realizado com jovens e adultos homens gays, a partir do aplicativo de encontros Tinder. Os autores defendem a ideia de que as histórias desenvolvidas através dessa forma de relacionamento produzem 
pedagogias sexuais que orientam alguns aspectos da vida dos sujeitos, como o cuidado com o corpo, a curtição da vida e as múltiplas possibilidades de paquera online. Sales, Souza e Peres (2017), por sua vez, discutem os processos de subjetivação que estão relacionados com as travestis, a partir do debate promovido pelas novas configurações de expressar os gêneros, as corporalidades e as sexualidades. Os autores encontram o espaço da escola como cenário que potencializa as variadas ordens de construções identitárias binárias e que a presença de estudantes travestis promove o rompimento com as lógicas dominantes e já postas. Por fim, o trabalho de Barros e Colaço (2013) analisou os sentidos produzidos por jovens sobre o tema da sexualidade, a partir de um grupo de discussão realizado em uma escola pública em Fortaleza (CE). Os jovens sujeitos da pesquisa relacionam sexualidade com risco, em sobressalto às relações de sexualidade com prazer, por exemplo.

Os trabalhos selecionados na categoria juventudes e sexualidades apontaram para o reconhecimento da diversidade como categoria fundante nas juventudes contemporâneas, além do fato de que a presença do diferente em cenários do cotidiano dos sujeitos - como a escola aponta para a criação e incentivo de novas concepções de mundo. Os cuidados com o corpo e à prevenção relacionados à sexualidade despontam como elementos de destacada importância para os jovens, já que os mesmos colocam as preocupações com o risco antes do prazer, por exemplo. $\mathrm{O}$ fato de se constituir, no corpus da investigação, uma categoria composta por trabalhos que discutiram as temáticas relacionadas à sexualidade juvenil aponta para os ganhos sociais que tais pesquisas vêm apresentadas, também como devolutivas e alerta à sociedade.

Nos processos de construção do estado da arte de específicas realidades investigativas, a observação e as análises exploradas em relação às tendências metodológicas dos estudos constituem-se elemento fundamental, já que, por meio desse tipo de apreciação, distinguem-se as principais estratégias de trabalho das pesquisas que versaram sobre 0 tema das juventudes e da educação. O quadro 3 aponta essas principais tendências.

Quadro 3 - tendências metodológicas

\begin{tabular}{|l|c|c|c|c|}
\hline \multicolumn{5}{|c|}{ Quanto à abordagem } \\
\hline \multicolumn{1}{|c|}{ Índice } & $N$ & $\%$ & \multicolumn{1}{c|}{ Referência (primeiro autor, ano) } \\
\hline Qualitativa & 13 & $100 \%$ & $\begin{array}{l}\text { Pinheiro (2020); Rosistolato (2013); Mesquita (2013); Souza (2012); Takeiti } \\
\text { (2019); Barros (2013); Imbrizi (2019); Sales (2017); Feltes (2019); Santos } \\
(2019) ; \text { Villa (2015); Vazquez (2017); Silva Júnior (2020). }\end{array}$ \\
\hline \multicolumn{3}{|c|}{ Quanto ao instrumento } \\
\hline \multicolumn{1}{|c|}{ Índice } & $N$ & $\%$ & Referência (primeiro autor, ano) \\
\hline $\begin{array}{l}\text { Trabalho de } \\
\text { grupos }\end{array}$ & 5 & $38 \%$ & Mesquita (2013); Barros (2013); Imbrizi (2019); Feltes (2019); Villa (2015). \\
\hline Entrevista & 4 & $31 \%$ & Takeiti (2019); Feltes (2019); Villa (2015); Silva Júnior (2020). \\
\hline
\end{tabular}




\begin{tabular}{|c|c|c|c|}
\hline Observações & 3 & $24 \%$ & Rosistolato (2013); Barros (2013); Feltes (2019). \\
\hline $\begin{array}{l}\text { Trabalho/Diá- } \\
\text { rio de Campo }\end{array}$ & 3 & $24 \%$ & Pinheiro (2020); Takeiti (2019); Feltes (2019). \\
\hline Questionário & 1 & $8 \%$ & Rosistolato (2013). \\
\hline Outros & 5 & $38 \%$ & $\begin{array}{l}\text { Pinheiro (2020); Souza (2012); Sales (2017); Santos (2019); Vazquez } \\
\text { (2017). }\end{array}$ \\
\hline \multicolumn{4}{|r|}{ Quanto ao método de análise } \\
\hline Índice & $N$ & $\%$ & Referência (primeiro autor, ano) \\
\hline $\begin{array}{l}\text { Análise de } \\
\text { conteúdo }\end{array}$ & 7 & $54 \%$ & $\begin{array}{l}\text { Rosistolato (2013); Mesquita (2013); Takeiti (2019); Imbrizi (2019); Feltes } \\
\text { (2019); Villa (2015); Silva Júnior (2020). }\end{array}$ \\
\hline $\begin{array}{l}\text { Análise biblio- } \\
\text { gráfica }\end{array}$ & 2 & $15 \%$ & Souza (2012); Sales (2017). \\
\hline $\begin{array}{l}\text { Análise de nar- } \\
\text { rativas }\end{array}$ & 2 & $15 \%$ & Pinheiro (2020); Villa (2015). \\
\hline Outras & 3 & $24 \%$ & Barros (2013); Santos (2019); Vazquez (2017). \\
\hline \multicolumn{4}{|r|}{ Quanto à população } \\
\hline Índice & $N$ & $\%$ & Referência (primeiro autor, ano) \\
\hline Jovens & 13 & $100 \%$ & $\begin{array}{l}\text { Pinheiro (2020); Rosistolato (2013); Mesquita (2013); Souza (2012); Takeiti } \\
\text { (2019); Barros (2013); Imbrizi (2019); Sales (2017); Feltes (2019); Santos } \\
\text { (2019); Villa (2015); Vazquez (2017); Silva Júnior (2020). }\end{array}$ \\
\hline Professores & 1 & $8 \%$ & Villa (2015). \\
\hline Adultos & 1 & $8 \%$ & Silva Júnior (2020). \\
\hline \multicolumn{4}{|r|}{ Quanto ao cenário } \\
\hline Índice & $N$ & $\%$ & Referência (primeiro autor, ano) \\
\hline Escola & 5 & $38 \%$ & Rosistolato (2013); Barros (2013); Sales (2017); Feltes (2019); Villa (2015). \\
\hline Cidade & 4 & $31 \%$ & Pinheiro (2020); Mesquita (2013); Takeiti (2019); Vazquez (2017). \\
\hline Universidade & 2 & $15 \%$ & Imbrizi (2019); Santos (2019). \\
\hline Redes Sociais & 1 & $8 \%$ & Silva Júnior (2020). \\
\hline Múltiplos & 1 & $8 \%$ & Souza (2012). \\
\hline
\end{tabular}

Fonte: Banco de dados da Pesquisa (2021). Organização: o autor (2021)

Em relação à abordagem dos textos, $100 \%(n=13)$ trataram-se de trabalhos de cunho qualitativo, apontado para o grande destaque que essa abordagem investigativa ganha nos estudos sobre juventudes. Tal constatação, somada ao fato de que nenhum dos 
textos analisados tratou-se de investigação de cunho unicamente quantitativo, põe em evidência as múltiplas formas de enfoques e abordagens qualitativas possíveis, na pesquisa sobre juventudes e educação.

Ao verificar os instrumentos de coletas das pesquisas nos textos que compuseram o corpus da presente investigação, a maioria $(38 \%, n=5)$ utilizou-se de trabalhos de grupos (grupo focal, discussões em grupo, roda de conversa), como forma de coleta de dados. Na sequência, a utilização das entrevistas, com 31\% $(n=4)$ também foi apontada, seguida de observações em geral e trabalhos de campo, ambas com $24 \%(n=3)$ cada. Ainda, o questionário figurou em $8 \%(n=1)$ das investigações. Os dados relativos aos instrumentos de coleta de dados das pesquisas que formaram os artigos analisados evidenciaram, igualmente, que a maioria dos trabalhos utilizou-se da perspectiva dos multi-métodos (OLIVEIRA, 2015), na medida em que adotaram mais de uma forma de coleta de dados, utilizadas em conjunto, para as pesquisas que foram realizadas. Os trabalhos de grupos, como estratégias mais evidentes renova o ideário de que se faz fundamental ouvir os jovens, quando se pesquisa com esses sujeitos (DUARTE, 2004), em especial no seu caráter de coletividade. A escuta às demandas, percepções e reivindicações das juventudes constituem-se em elemento central e potencializador para decifrar as questões trazidas pelos jovens, em especial em relação aos espaços pelos quais transitam e às experiências e trajetórias educativas.

Ao conferir os métodos de análise dos dados coletados nas pesquisas, a análise de conteúdo apontou em $54 \%(n=7)$ dos trabalhos, seguida da análise bibliográfica $(15 \%, n$ $=2$ ) e das análises narrativas $(15 \%, n=2)$. É possível correlacionar o uso da técnica de análise de conteúdo, na medida em que a maioria das coletas de dados se deu por meio dos trabalhos de grupos e das entrevistas. Nessa leitura, e em conjunto ao proposto por Bardin (1977), a análise de conteúdo passa a permitir a criação de categorias que facilitam o trabalho analítico, dispondo os dados analisados em unidades temáticas das quais outras análises podem ser empregadas. Apreender, deste modo, as categorias das demandas trazidas pelas juventudes ancoram, ao mesmo tempo, em pensar em novas estratégias de abordagem e também de apreciação das demandas desses sujeitos.

Em relação aos sujeitos das investigações analisadas, a totalidade $(n=13)$ constituiu-se de jovens, sendo, em uma leitura etária, os sujeitos compreendidos na faixa etária dos 15 aos 29 anos (BRASIL, 2013). Além de trabalhar com as juventudes, um trabalho (8\%) debruçou-se na pesquisa sobre jovens e seus professores, ou seja, um estudo das realidades escolares e, ainda, outro trabalho (8\%) além de utilizar jovens como sujeitos trabalhou com adultos, sendo uma pesquisa realizada em redes sociais. $O$ fato da totalidade dos artigos discutirem e terem como sujeitos os jovens contemporâneos demonstra não apenas os esforços dos investigadores das juventudes em manter foco analítico estável no mesmo grupo social, como também expande o debate entre a pesquisa no campo das 
juventudes, como sujeitos sociais e de interações coletivas com as demais questões da sociedade.

Por fim, em relação aos cenários das pesquisas analisadas, a escola emergiu como espaço de $38 \%(n=5)$ das investigações, ao ponderar uma conjuntura na qual se identificaram trabalhos relacionados ao campo das juventudes e da educação, a escola ganha destaque analítico, no sentido de ser o espaço principal - mas não o único - no qual a educação ocorre. Prova disso é a presença da universidade, como cenário de $15 \%(n=2)$ das investigações, em conjunção com os $8 \%(n=1)$ de pesquisas realizadas nas redes sociais e em múltiplos cenários. Ainda, nessa leitura, a cidade foi o cenário de investigação de $31 \%$ $(n=4)$ dos trabalhos, o que aponta para a perspectiva de uma cidade que educa os jovens (OLIVEIRA, 2018) e, ainda, de jovens que deixam as suas marcas no espaço urbano, transformando o espaço pelo qual circulam e dizendo, com seus corpos ${ }^{10}$, que a cidade também é seu espaço de direito, assim como suas existências.

\section{PARA SEGUIR PENSANDO}

Nesse trabalho, o principal objetivo consistiu em realizar a construção do estado da arte das publicações, em periódicos com Qualis A2, de Universidades Federais brasileiras, sobre o campo das juventudes e educação, tendo sido adotado o recorte temporal no período compreendido entre os anos de 2011 e 2020. Para tanto, foi realizada pesquisa de cunho bibliográfico, em formato de estado da arte no repositório da CAPES e nos bancos de dados das 16 revistas que foram selecionadas para análise. A busca resultou na formação de um corpus composto por 13 artigos científicos, que foram analisados e dos quais foram extraídas multíplices dados e informações.

Em relação aos periódicos analisados, apenas em 7 dos 16 selecionados foram encontrados trabalhos, sendo das regiões sul, sudeste e nordeste do Brasil. O ano com maior número de trabalhos foi 2019 , não tendo sido constatada regularidade na produção e sendo a mesma considerada baixa em termos numérico-quantitativos. As expressões "jovens", "política", "educação" e "social" foram as mais evidentes no conjunto dos artigos, o que as colocou não apenas como válidas para a continuidade analítica, mas que também reforçou o compromisso dos pesquisadores das juventudes, em ponderar sobre o campo da educação, da sociedade e da política com especial cuidado sintético. Ainda, as relações encontradas nas principais expressões dos textos avaliados admitiram distinguir maior inquietação no entendimento dos sentidos que jovens atribuem aos variados elementos da vida cotidiana.

10 São amplos os estudos que vêm apontando para o crescente e acelerado aumento do extermínio das juventudes negras nas regiões de periferia das metrópoles brasileiras. Exemplo disso são as pesquisas de Scherer (2018), que apontam para as violências territoriais juvenis e o caráter descartável da vida desses sujeitos. 
Três categorias analíticas dos textos puderam ser constituídas, já que alguns trataram de questões específicas das juventudes periféricas; outros evidenciaram as discussões sobre as culturas juvenis contemporâneas; e outros, ainda, trataram-se das questões relacionadas às sexualidades juvenis. As discussões empregadas nos textos alocam os jovens, essencialmente, como sujeitos de direitos, como protagonistas de suas trajetórias e reconhecem as suas culturas, as suas demandas e as suas preocupações.

Em relação às tendências metodológicas dos textos, a maioria tratou-se de pesquisa de cunho qualitativo, com os trabalhos de grupos e as entrevistas como principais instrumentos de coleta de dados, a análise de conteúdo como principal técnica de análise desses dados, os jovens como sujeitos centrais das investigações e a escola como um dos principais cenários das pesquisas. O contexto encontrado aponta para o recente direcionamento que as pesquisas do campo das juventudes e educação vêm estabelecendo e atravessando, e, ainda, abre margem para a discussão de outras e novas apropriações metodológicas.

Para além das tendências teórico-metodológicas verificadas, alguns silenciamentos puderem ser sentidos, dentre eles é possível destacar a necessidade de maior número de pesquisas que se dediquem aos estudos das múltiplas etapas dos processos educativos dos jovens, dentre esses: o ensino médio, a educação de jovens e adultos, o ensino superior e a pós-graduação, por exemplo. Ainda, há necessidade do debate acerca das questões educativas da dimensão do trabalho - ou das consequências de sua ausência - na vida dos jovens. Mesmo reconhecendo que a especificidade e qualidade dos trabalhos de cunho qualitativo seja ampla e de necessário emprego nas pesquisas sobre as juventudes e educação, a ausência de produção de dados quantitativos primários restou evidenciada, uma vez que a maioria dos trabalhos buscou em fontes secundárias tais dados. Não se demoniza, portanto, a utilização de questionários e de análise estatística para a produção de dados nas pesquisas sobre as juventudes, o que se aconselha, para tal, é a associação de técnicas de coleta de dados, como já é realizada, a partir do trabalho com os multi-métodos.

Avigorar e compelir na busca pelas garantias da constituição de um campo do saber, como vem sendo o caso das juventudes trata-se de tarefa elementar para proporcionar o reconhecimento daqueles que edificam diariamente a pesquisa no campo cujo principal objetivo é distinguir as juventudes e suas múltiplas formas de ser e de estar. Os desafios encontrados por pesquisadores do campo também aperfeiçoam a pesquisa e organizam as trajetórias que são permanentemente construídas, nos saberes, fazeres e moldagens da pesquisa. Em tempos sombrios nos quais as ciências humanas - em especial - vêm sofrendo duros e constantes ataques por parte inclusive daqueles que deveriam incentivar e promover a ciência, garantir a autonomia dos pesquisadores, a liberdade de expressão e de cátedra, bem como o aumento do fomento e do financiamento da pesquisa são alguns dos subsídios que permanecem constantes na agenda dos investigadores, e, portanto, o caso daqueles que investigam as juventudes não é diferente. Que a luta por justiça social e 
a consequente redução das desigualdades possa proporcionar a garantia de esperançar ${ }^{11}$ em tempos melhores.

Há, por fim, o entendimento de que a construção do estado da arte não se trata apenas da simples repetição do que outros pesquisadores já construíram em seus trabalhos. Trata-se de um exercício comprometido de pesquisa, busca, seleção, reflexão e curadoria sobre o que já fora construído e escrito por outros, antes de quem o escreve agora. Por isso, não é possível, nem pela constituição do estado da arte, nem por outra forma qualquer, saber daqueles processos, situações e vivências particulares pelas quais cada pesquisadora e pesquisador passaram durante seus ofícios de pesquisa e, em relação a isso, há grande respeito e admiração.

11 Esperançar, no sentido Freireano, uma espera não passiva, mas calcada na esperança que todo aquele que trabalha no campo da educação deve ter (FREIRE, 2001) 


\section{REFERÊNCIAS}

ABRAMO, Helena Wendel. Considerações sobre a tematização social da juventude no Brasil. Revista Brasileira de Educação, São Paulo, n. 5, 1997. Disponível em: http://www.clam.org.br/bibliotecadigital/uploads/publicacoes/442_1175_abramowendel.pdf. Acesso em: 20 jan. 2021.

ABRAMOVAY, Miriam et al. Juventudes: outros olhares sobre a diversidade. Brasília: Ministério da Educação, Secretaria de Educação Continuada, Alfabetização e Diversidade; Unesco, 2007. Disponível em: https://bibliotecadigital.mdh.gov.br/jspui/handle/192/160. Acesso em: 20 jan. 2021.

ABRAMO, Helena Wendel; LEÓN, Oscar Dávila. Juventude e adolescência no Brasil: referências conceituais. 1. ed. São Paulo: Ação Educativa, 2005.

BARDIN, Laurence. Análise de conteúdo. Lisboa: Edições 70, 1977.

BARROS, João Paulo Pereira et al. "Meu prazer agora é risco": sentidos sobre sexualidade entre jovens de um grupo sobre saúde. Fractal (UFF), v. 25, n. 01, 2013. Disponível em: https://periodicos. uff.br/fractal/article/view/4929. Acesso em: 20 jan. 2021.

BRASIL. Lei 12.852 de 5 de agosto de 2013. Institui o Estatuto da Juventude e dispõe sobre os direitos dos jovens, os princípios e diretrizes das políticas públicas de juventude e o Sistema Nacional de Juventude - SINAJUVE. Disponível em: http://www.planalto.gov.br/ccivil_03/_Ato20112014/2013/Lei/L12852.htm. Acesso em: 20 jan. 2021.

BRASIL. Ministério da Saúde. Conselho Nacional de Saúde. Resolução $\mathbf{n}^{\circ} \mathbf{5 1 0}$, de 7 de abril de 2016. Diário Oficial da República Federativa do Brasil, Brasília, DF, 24 maio 2016. Seção 1. p. 44-46. Disponível em: https://bvsms.saude.gov.br/bvs/saudelegis/cns/2016/res0510_07_04_2016. html. Acesso em: 20 jan. 2021.

CORROCHANO, Maria Carla; DOWBOR, Monika; JARDIM, Fabiana Augusta Alves. Juventudes e participação política no Brasil do século XXI quais horizontes? Laplage em Revista, v. 4, n. 1, 2018. Disponível em: https://dialnet.unirioja.es/servlet/articulo?codigo=6275807. Acesso em: 20 jan. 2021.

DAYRELL, Juarez. A escola "faz" as juventudes? Reflexões em torno da socialização juvenil. Educação e Sociedade, v. 28, n. 100, 2007. Disponível em: https://www.scielo.br/scielo.php?pid=S0101-73302007000300022\&script=sci_abstract\&tlng=es. Acesso em: 20 jan. 2021.

DUARTE, Rosália. Entrevistas em pesquisas qualitativas. Educar em Revista, v. 24, 2004. Disponível em: https://www.scielo.br/scielo.php?pid=S0104-40602004000200011\&script=sci_arttext\&tIng=pt. Acesso em: 20 jan. 2021.

FEIXA PAMPOLS, Carles. De jovenes, bandas y tribus. 1. ed. Barcelona: Ariel, 1998.

FELTES, Alessandra Fernandes et al. A percepção das juventudes a respeito dos seus processos de identidades e suas apropriações para além do jogador Neymar. Movimento (UFRGS), v. 25, 2019. Disponível em: https://seer.ufrgs.br/Movimento/article/view/86901/55149. Acesso em: 20 jan. 2021.

FREIRE, Paulo. Pedagogia dos sonhos possíveis. São Paulo: Editora UNESP, 2001. 
FRIGERI, Mônica; MONTEIRO, Marko Synésio Alves. Qualis Periódicos: indicador da política científica no Brasil? Estudos de Sociologia, Araraquara, v. 19, n. 37, 2014. Disponível em: https:// periodicos.fclar.unesp.br/estudos/article/view/6266/0. Acesso em: 20 jan. 2021.

FURTADO, Celso. O nordeste: reflexões sobre uma política alternativa de desenvolvimento. Revista Brasileira de Economia Política, v. 4, n. 3, 1984. Disponível em: https://centrodeeconomiapolitica.org.br/rep/index.php/journal/article/view/1892. Acesso em: 20 jan. 2021.

GALEANO, Eduardo. As veias abertas da América Latina. Tradução de Galeno de Freitas. 39a ed. Rio de Janeiro: Paz e Terra, 2000.

GIL, Antônio Carlos. Como elaborar projetos de pesquisa. 4. ed. São Paulo: Atlas, 2007.

IMBRIZI, Jaquelina Maria et al. Cultura hip-hop e enfrentamento à violência: uma estratégia universitária extensionista. Fractal (UFF), v. 31, 2019. Disponível em: https://periodicos.uff.br/fractal/ article/view/29041/. Acesso em: 20 jan. 2021.

JUNGBLUTH, Adriana; SOUEN, Jacqueline Aslan. A importância da política de valorização do salário mínimo para a região Nordeste. Leituras de Economia Política, Campinas, v. 16, 2010. Disponível em: https://www.eco.unicamp.br/images/arquivos/artigos/3125/05\%20ADRIANA.pdf. Acesso em: 20 jan. 2021.

LEVIN, Jack Fox. Estatística para ciências humanas. 9.ed. São Paulo: Pearson Prentice Hall, 2007.

MESQUITA, Marcos Ribeiro et al. Juventudes, movimentos e culturas: a participação política de jovens na cidade de Maceió. Estudos de Psicologia (UFRN), v. 18, n. 02, 2013. Disponível em: http://www.scielo.br/scielo.php?script=sci_arttext\&pid=S1413-294X2013000200025\&lng=pt\&nrm=iso. Acesso em: 20 jan. 2021.

MOROSINI, Marilia Costa; FERNANDES, Cleoni Maria Barbosa. Estado do Conhecimento: conceitos, finalidades e interlocuções. Educação Por Escrito, Porto Alegre, v. 5, 2014. Disponível em: https://revistaseletronicas.pucrs.br/ojs/index.php/porescrito/article/view/18875. Acesso em: 20 jan. 2021.

NOVAES, Regina. Juventude, religião e espaço público: exemplos "bons para pensar" tempos e sinais. Religião e Sociedade, Rio de Janeiro, v. 32, n. 01, 2012. Disponível em: https://www.scielo.br/ scielo.php?pid=S0100-85872012000100009\&script=sci_arttext\&tlng=pt. Acesso em: 20 jan. 2021.

OLIVEIRA, Fabiana Luci de. Triangulação metodológica e abordagem multimétodo na pesquisa sociológica: vantagens e desafios. Ciências Sociais UNISINOS, v. 51, n. 02, 2015. Disponível em: http://revistas.unisinos.br/index.php/ciencias_sociais/article/view/6828. Acesso em: 20 jan. 2021.

OLIVEIRA, Victor Hugo Nedel. (De) marcando a cidade: vivências urbanas de jovens-estudantes do Colégio de Aplicação da UFRGS. Cadernos do Aplicação, v. 31, n. 01, 2018. Disponível em: https://www.seer.ufrgs.br/CadernosdoAplicacao/article/view/82695. Acesso em: 20 jan. 2021.

OLIVEIRA, Victor Hugo Nedel. Jovens olhares sobre a cidade: lugares e territórios urbanos de estudantes porto-alegrenses. 2020. 213f. Tese (Doutorado em Educação) - Escola de Humanida- 
des, Programa de Pós-Graduação em Educação, Pontifícia Universidade Católica do Rio Grande do Sul, Porto Alegre, 2020a. Disponível em: http://tede2.pucrs.br/tede2/handle/tede/9109. Acesso em: 20 jan. 2021.

OLIVEIRA, Victor Hugo Nedel. Juventudes, escola e cidade na pandemia da Covid-19. Boletim de Conjuntura, v. 04, n. 10, 2020b. Disponível em: https://revista.ufrr.br/boca/article/view/OliveiraNedel. Acesso em: 20 jan. 2021.

PAIS, José Machado et al. Juventudes contemporâneas, cotidiano e inquietações de pesquisadores em educação - uma entrevista com José Machado Pais. Educar em Revista, v. 33, n. 64, 2017. Disponível em: https://revistas.ufpr.br/educar/article/view/50119/. Acesso em: 20 jan. 2021.

PAIS, José Machado. Culturas Juvenis. 1. ed. Lisboa: Imprensa Nacional-Casa da Moeda, 1993.

PINHEIRO, Leandro Rogério. Individuação em periferias e apropriação da educação: considerações desde a produção de narrativas. Cadernos de Pesquisa (UFMA), v. 27, n. 01, 2020. Disponível em: http://www.periodicoseletronicos.ufma.br/index.php/cadernosdepesquisa/article/view/14756. Acesso em: 20 jan. 2021.

REIS, Rosemeire. Juventudes no ensino médio: sentidos atribuídos à escola e aos planos de futuro. Latitude, v. 6, n. 1, 2012. Disponível em: Acesso em: https://www.seer.ufal.br/index.php/latitude/ article/view/858. 20 jan. 2021.

ROSISTOLATO, Rodrigo Pereira da Rocha et al. Juventudes populares e projetos educacionais: construção e fortalecimento de redes de solidariedade, afeto e sociabilidade. Cadernos de Pesquisa (UFMA), v. 20, n. 03, 2013. Disponível em: http://www.periodicoseletronicos.ufma.br/index.php/ cadernosdepesquisa/article/view/2258. Acesso em: 20 jan. 2021.

SALES, Adriana et al. Travestis brasileiras e escola: problematizações sobre processos temporais em gêneros, sexualidades e corporalidades nômades. Fractal (UFF), v. 29, n. 01, 2017. Disponível em: https://periodicos.uff.br/fractal/article/view/5120. Acesso em: 20 jan. 2021.

SANTOS, Milton. A região concentrada e os circuitos produtivos. Texto apresentado como parte do relatório de pesquisa do projeto O Centro Nacional: Crise Mundial e Redefinição da Região Polarizada, 1986 (datilografado).

SANTOS, Boaventura Souza; MENESES, Maria Paula. Epistemologias do Sul. Coimbra: Almeidina, 2009.

SANTOS, Edmea Oliveira dos et al. Os selfies e o corpo tombamento: reflexões a partir de uma autoimagem sonora. Perspectiva (UFSC), v. 37, n. 01, 2019. Disponível em: https://periodicos.ufsc. br/index.php/perspectiva/article/view/2175-795X.2019.e53039. Acesso em: 20 jan. 2021.

SCHERER, Giovane Antônio. Emancipação, Ponta Grossa, v. 18, n. 2, 2018. Disponível em: http:// www.revistas2.uepg.br/index.php/emancipacao. Acesso em: 20 jan. 2021.

SILVA JÚNIOR, Alcidesio Oliveira da et al. Amor, sexo e distância física: Pedagogias do Webnamoro na pandemia da Covid-19. Revista Educação em Questão (UFRN), v. 58, n. 58, 2020. Disponível em: https://periodicos.ufrn.br/educacaoemquestao/article/view/21741. Acesso em: 20 jan. 2021. 
SOUZA, Candida et al. Faces da juventude brasileira: entre o ideal e o real. Estudos de Psicologia (UFRN), v. 17, n. 03, 2012. Disponível em: https://www.scielo.br/pdf/epsic/v17n3/02.pdf. Acesso em: 20 jan. 2021.

SPOSITO, Marilia Pontes. Estudos sobre juventude em Educação. Revista Brasileira de Educação, São Paulo, n. 5, 1997 (datilografado).

TAKEITI, Beatriz Akemi; VICENTIN, Maria Cristina Gonçalves. A produção de conhecimento sobre juventude(s), vulnerabilidades e violências: uma análise da pós-graduação brasileira nas áreas de Psicologia e Saúde (1998-2008). Saúde e Sociedade, v. 24, n. 3, 2015. Disponível em: https://www. scielosp.org/pdf/sausoc/2015.v24n3/945-963/pt Acesso em: 20 jan. 2021.

TAKEITI, Beatriz Akemi et al. Juventude(s) periférica(s) e subjetivações: narrativas de (re)existência juvenil em territórios culturais. Fractal (UFF), v. 31, 2019. Disponível em: https://periodicos.uff.br/ fractal/article/view/29028 Acesso em: 20 jan. 2021.

VAZQUEZ, Melina et al. Activismo juvenil en partidos con gestiones de gobierno a nivel subnacional en Argentina (2007-2015). Revista de Sociologia e Política (UFPR), v. 25, n. 64, 2017. Disponível em: https://revistas.ufpr.br/rsp/article/view/57135 Acesso em: 20 jan. 2021.

VILLA, Alejandro. Las condiciones del aprendizaje escolar, las culturas juveniles y uso de TICs en el ingreso a la Escuela Media: Ios problemas en la transmisión entre jóvenes y profesores. Perspectiva (UFSC), v. 33, n. 02. 2015. Disponível em: https://periodicos.ufsc.br/index.php/perspectiva/ article/view/2175-795X.2015v33n2p613. Acesso em: 20 jan. 2021.

WEISHEIMER, Nilson. Sobre a invisibilidade social das juventudes rurais. Desidades, v. 1, n. 1, 2013. Disponível em: http://desidades.ufrj.br/featured_topic/sobre-a-invisibilidade-social-das-juventudes-rurais/. Acesso em: 20 jan. 2021.

ZANELLA, Andrea Vieira et al. Jovens, juventude e políticas públicas: produção acadêmica em periódicos científicos brasileiros (2002 a 2011). Estudos de Psicologia (Natal), v.18, n.2, 2013. Disponível em: https://www.scielo.br/scielo.php?pid=S1413-294X2013000200019\&script=sci_arttext\&tlng=pt. Acesso em: 20 jan. 2021. 